\title{
STORAGE OF POISONS IN THE HOMES OF FAMILIES WITH SMALL CHILDREN
}

\author{
BY \\ RAGNAR BERFENSTAM AND JAN BESKOW \\ From the Department of Social Medicine, Uppsala, and the Department of Social Medicine, Umea, Sweden
}

Great attention has been paid all over the world during recent years to the subject of poisoning in children, and several workers have shown that in Sweden also the problem is important. Berfenstam (1954, 1958), for example, estimated the number of cases of poisoning treated in the Pediatric and Ear, Nose and Throat departments in Sweden as 2,000 to 3,000 annually.

It is usually small children who are the victims of accidental poisoning. Karlsson (1955), in a study of about 3,000 cases of poisoned children in Stockholm, found a rapidly increasing frequency from the age of 9 months, reaching a maximum at 11 to 15 months, followed by a slow decline. 81 per cent. of the poisonings occurred in children less than 3 years old. Both Lindquist (1954), in data from Lund, and Berfenstam, Ehrenpreis, Ekström, Garsten, and Myrin (1950) showed similar age distributions.

Practical measures of different kinds have been taken in Sweden for the prevention of accidental poisoning in children. A joint committee to campaign against accidents to children has repeatedly pointed out the importance of such measures. It may be mentioned, in particular, that in Sweden different types of safety locks and stoppers have been devised (Christiansson, 1954; Christiansson and Berfenstam, 1958; Myrin, Berfenstam, and Karlsson, 1960); much propaganda has been issued concerning them, and the use of secure medicine cupboards has also been recommended.

The large number of poisoning cases and the increasing quantities of poisonous medicines and chemical preparations in domestic use (pest and vermin destroyers, cleaning powders and fluids, polishes, disinfectants, etc.) justifies more detailed studies of the problem (Barr, 1958). It is well known that behind every accident there is a complex mechanism (Jacobziner, 1957; Koumans, 1960). One method of studying the problem which may be of great value is to obtain detailed information through home visits after cases of accidental poisoning (McIntire and Simmons, 1960).

In this paper a study is presented of one predisposing factor: the too easy access to poisonous preparations. In this type of study objectivity and replicability is of primary importance from the point of view of method, and one of the aims of the present survey is to establish an acceptable method of investigation with especial regard to these qualities.

\section{METHOD*}

Relevant information was collected, according to a specially designed questionnaire, by interviewers visiting families with small children. The presence of medicines and household chemicals in the home, and the availability of suitable storage space was recorded. According to previously established criteria, the method of storage was assessed with regard to the risks of poisoning to the children, and also with regard to the way in which the available storage space was utilized.

The investigation was carried out in an industrial town of about 75,000 inhabitants. The families to be investigated were chosen from the records of the

*Avo Rand, lecturer at the Institute of Statistics, Stockholm Univer123 
child welfare clinics. This procedure is justified by the fact that almost all children in this town are entered in these records $(98.7$ per cent. of all children in 1958).

Since the number of cases of poisoning among children attains a maximum at the age of 1 to 2 years, it was decided to investigate families with children in this age group.

CHILDREN STUdIED.-The investigation was carried out in the late autumn of 1959, on children living in the town who had been born there between October 1, 1957, and September 30, 1958, and who attended the child welfare clinics. 20 per cent. of these children were selected at random for a sample test. The over-representation caused by twins was reduced by the fact that the interview only took place when a second twin was selected. When the children who had moved from the town had also been excluded, we were left with 214 children still living in the town aged 13 to 26 months.

The poisoning risks threatening the children were estimated by studying the milieu in which the child spent the greatest part of the day. One child spent the whole day at a day nursery, but this lay outside the aim of the study. A number of children spent part of the day with families other than their own, in socalled "family day-nurseries". When this amounted to more than 5 hours daily, the family day-nursery was investigated instead of the child's actual home.

Home Visits.-Because of the nature of the investigation, it was necessary for the home visits to be carried out by persons whom the families were willing to accept and who would therefore be able to obtain a good insight into their homes. The six nurses from the town's child welfare clinics were therefore employed as interviewers, as they were already well known to the families through their routine work.

In as many cases as possible the home visits were made without previous warning, and $188(91 \cdot 3$ per cent.) of the families had no knowledge that the nurse was to be expected.

INTERVIEWS.-The home visit included an interview with the child's guardian, usually the mother, during which information was obtained concerning the presence in the home of medicines and technical preparations. No inquiry was made concerning any individual medicines or household chemicals, but only concerning certain groups of preparations. Among the medicines these groups were prescribed cough medicines, nasal drops, soporifics, aspirin and codeine preparations and other analgesics, iron tablets, and heart medicines. Inquiry was also made about eleven groups of technical preparations, including washing-up and washing substances (both the dangerous and the relatively harmless), metal polish, furniture polish, garden pest destroyers (nicotine preparations), and rat poison.

The person interviewed was also asked to describe the existing arrangements in the home for storing medicines (medicine cupboard, safety stoppers) and household chemicals (cleaning cupboard with lock, cupboard with lock inside the cleaning cupboard, cupboard with lock under the sink, safety locks), and also how these were used. The interviewer also asked to see the kitchen and bathroom cupboards for herself, in order to verify the information given.

The person interviewed was also asked whether there had been any case of poisoning in the family, and if so whether this had led them to take any preventive measures.

The interviewers also assessed whether the medicines and household chemicals in the home were accessible to children or not. There was some diffculty here in producing a uniform system, and it was decided to base the assessments on the possible capabilities of a 24-month-old child, and the following standards were set up for storage places which could be considered inaccessible:

(a) Locked cupboard with key removed, or cupboard supplied with effective safety lock.

(b) Unlocked cupboard with the handle inaccessible, i.e. more than $110 \mathrm{~cm}$. above steady articles on to which the child could climb, e.g. sink, chair pushed forward, etc.

(c) Any other inaccessible placing, i.e. situated more than $110 \mathrm{~cm}$. above a steady article.

Before the actual investigation was carried out, seventeen trial interviews were made, and on the basis of the experience thus gained, the questionnaire was altered somewhat. The changes made were such that the trial interviews, after being complemented by further information, could be analysed with the final questionnaire.

\section{MATERIAL}

214 families were selected for interview. In two cases the interview was refused, and in six cases the interview could not be carried out for other reasons (in four cases no-one was found at home on repeated visits, one family could not be interviewed as they spoke a foreign language, and one child, as mentioned above, spent the whole day at a day-nursery).

The total number of homes investigated was thus $206(96 \cdot 3$ per cent. of the possible total). 


\section{RESULTS}

Presence of Medicines and Household Chemicals and SafeTy ARrangements (Medicine Cupboards, Safety Stoppers, Cleaning Cupboards, etc.)

Medicines and household chemicals were found, as expected, in almost all families (Table I); in only eight families were they completely lacking. Usually there were medicines belonging to two groups, but about 15 per cent. of the families had medicines belonging to four or more groups. Those most commonly found were aspirin and codeine preparations and other analgesics, which were present in $92 \cdot 2$ per cent. of the homes.

TABLE I

PRESENCE OF MEDICINES AND HOUSEHOLD CHEMICALS IN THE HOME

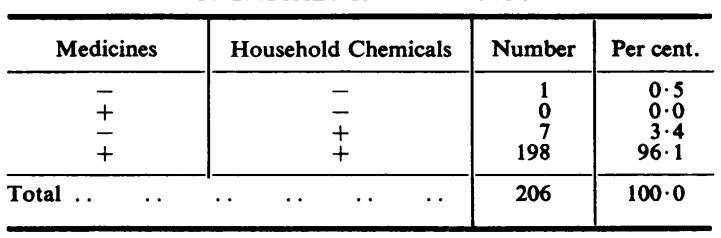

Household chemicals were even more common, but were completely lacking in one family. Most frequently the interviewers found household chemicals belonging to five different groups, but a quarter of the families had chemicals belonging to seven or more groups.

Special safety arrangements for the storage of medicines and household chemicals were found in very few homes (Table II).

TABLE II

PRESENCE OF SAFETY ARRANGEMENTS IN THE HOME

\begin{tabular}{|c|c|c|}
\hline Safety Arrangements & Number & Per cent. \\
\hline 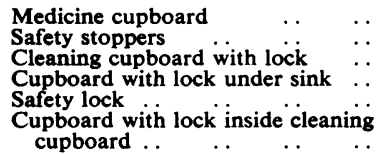 & $\begin{array}{r}16 \\
3 \\
80 \\
13 \\
10 \\
5\end{array}$ & $\begin{array}{r}7 \cdot 8( \pm 3 \cdot 3) \\
1 \cdot 5( \pm 1 \cdot 5) \\
38 \cdot 8( \pm 6 \cdot 0) \\
6 \cdot 3( \pm 3 \cdot 0) \\
4 \cdot 9( \pm 2 \cdot 6) \\
2 \cdot 4( \pm 1 \cdot 9)\end{array}$ \\
\hline
\end{tabular}

The 95 per cent. confidence intervals for the proportions in the whole population can be obtained from the figures in brackets which represent twice the standard errors of the sample estimates.

\section{Storage of Medicines and Household Chemicals}

One of the aims of the investigation was to attempt, following predetermined norms, to assess the safety of storage of medicines and household chemicals with regard to the poisoning risks to children (Table III).

\section{TABLE III}

METHOD OF STORING MEDICINES AND HOUSEHOLD CHEMICALS IN THE HOME

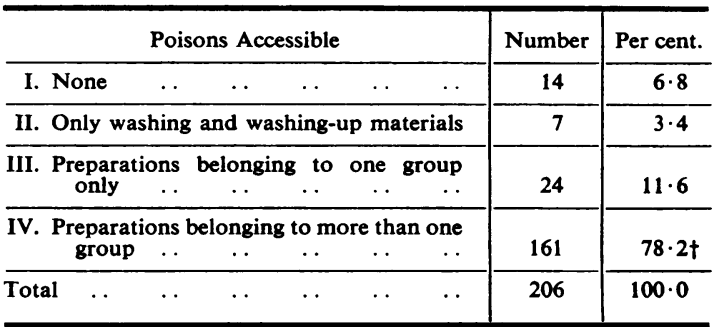

* In Groups III and IV the possible accessibility of washing and washing-up materials has not been considered.

tIn 45 (21.8 per cent.) of these families there were medicines belonging to at least two groups, plus household chemicals belonging to at least two groups, stored with access to children.

Only in homes where no chemicals are accessible to children can the method of storage be considered satisfactory. This was the case in only fourteen homes (6.8 per cent.). In a further seven families (3.4 per cent.), however, only washing and washingup materials (relatively harmless) were accessible, and this, even if with some doubt, was regarded as acceptable. In the remaining 185 families $(89 \cdot 8$ per cent.), the method of storage was regarded as unsatisfactory, i.e. one or more household chemicals apart from washing and washing-up materials and/or one or more groups of medicines were accessible to children.

The families investigated showed less care in the storage of household chemicals than in that of medicines (Tables IV and V, overleaf).

It is reasonable to suppose that a large quantity of medicines and household chemicals in a home increases the risk of unsatisfactory storage. In families with only one such preparation or none there is correspondingly little accessible to children. When these families were excluded and the rest of the material analysed, no definite relationship between the number of preparations and the method of storage could be shown.

\section{Use of Medicine and Cleaning Cupboards}

It was of interest to study whether the existing safety arrangements in the homes were used adequately. This should mean that all medicines and 
TABLE IV

STORAGE OF MEDICINES

\begin{tabular}{|c|c|c|c|c|c|}
\hline \multicolumn{4}{|c|}{ Medicines Accessible } & Number & Per cent. \\
\hline $\begin{array}{l}\text { None . } \\
\text { Belonging to } \\
\text { Belonging to }\end{array}$ & $\begin{array}{l}\text { one group only } \\
\text { two or more groups }\end{array}$ & $\begin{array}{l}\cdots \\
\cdots \\
\cdots\end{array}$ & $\begin{array}{l}\cdots \\
\cdots \\
\cdots\end{array}$ & $\begin{array}{l}84 \\
58 \\
64\end{array}$ & $\begin{array}{l}40 \cdot 8 \\
28 \cdot 2 \\
31 \cdot 0\end{array}$ \\
\hline Total & $\ldots$ & $\ldots$ & $\ldots$ & 206 & $100 \cdot 0$ \\
\hline
\end{tabular}

TABLE V

STORAGE OF HOUSEHOLD CHEMICALS

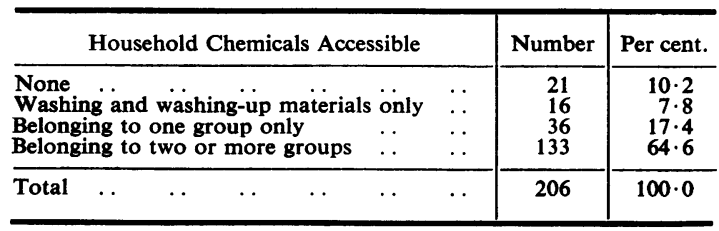

household chemicals are stored in the appropriate cupboards where such were available, with the cupboards locked and the key removed. This question was investigated in the families who had medicines and household chemicals and whose homes were provided with medicine and cleaning cupboards (Table VI).

TABLE VI

USE OF MEDICINE AND CLEANING CUPBOARDS*

\begin{tabular}{|c|c|c|c|c|}
\hline \multirow{3}{*}{ Use of Cupboard } & \multicolumn{4}{|c|}{ Cupboard } \\
\hline & \multicolumn{2}{|c|}{ Medicine } & \multicolumn{2}{|c|}{ Cleaning } \\
\hline & Number & Percent. & Number & Percent. \\
\hline $\begin{array}{c}\text { No Poisonous Preparations } \\
\text { in Cupboard } \\
\end{array}$ & 6 & $37 \cdot 5$ & 24 & $33 \cdot 8$ \\
\hline $\begin{array}{l}\text { Preparations Completely or } \\
\text { Partly Accessible in Cup- } \\
\text { board } \begin{array}{cccc} & \multicolumn{3}{c}{} \\
\end{array}\end{array}$ & 1 & $6 \cdot 2$ & 30 & $42 \cdot 3$ \\
\hline $\begin{array}{c}\text { Preparations Inaccessible in } \\
\text { Cupboard } \\
\end{array}$ & 9 & $56 \cdot 3$ & 17 & $23 \cdot 9$ \\
\hline Total & 16 & $100 \cdot 0$ & 71 & $100 \cdot 0$ \\
\hline
\end{tabular}

* Eighty homes containing cleaning cupboards with locks were found. In this Table only those 71 homes are included in which the cleaning cupboard was the only space provided with a lock, intended for the storage of household chemicals.

The inaccessibility of the medicines in the medicine cupboard was due in the majority of cases to the fact that it was situated high up; only in three cases were the cupboards locked and the key removed. In one family the medicine cupboard had to be designated as accessible, while another storage place which was also used was inaccessible.

The method of storage in the cleaning cupboard varied considerably. In only one case was the cupboard locked and the key removed. Less than half the families stored the chemicals in the cupboards so that they were completely or partly accessible, and one-third did not use the cupboards at all for the storage of household chemicals, which were kept in other places. In the relatively few cases in which the preparations were inaccessible, this was only because the cupboard in which they were kept was situated high up.

It was further found that 91.5 per cent. of the families with cleaning cupboards provided with a lock stored their household chemicals so that at least some of them were accessible, compared with 80.3 per cent. of the families without such cupboards. This was remarkable, since it would be expected that families with special cleaning cupboards would have a considerably better standard of safe storage than the others.

\section{Other ObServations}

In the sale of certain poisonous substances, it is required, according to the current regulations in Sweden, that special visible warnings should be printed on the package. To study the effects of these warnings, comparisons were made between the storage of vermin destroyers (nicotine preparations, etc.) and stain-removers, for which such warnings are required, with that of furniture polishes and washing and washing-up materials, for which they are not obligatory (Table VII). The most poisonous

TABLE VII

STORAGE OF HOUSEHOLD CHEMICALS WITH AND WITHOUT WARNING LABELS

\begin{tabular}{|c|c|c|c|c|c|c|c|}
\hline \multirow{3}{*}{\multicolumn{2}{|c|}{ Warning Labels }} & \multicolumn{4}{|c|}{ Storage } & & \\
\hline & & \multicolumn{2}{|c|}{$\begin{array}{l}\text { Completely } \\
\text { Inaccessible }\end{array}$} & \multicolumn{2}{|c|}{$\begin{array}{l}\text { Completely } \\
\text { or Partly } \\
\text { Accessible }\end{array}$} & \multicolumn{2}{|c|}{ Total } \\
\hline & & No. & $\begin{array}{l}\text { Per } \\
\text { cent. }\end{array}$ & No. & $\begin{array}{l}\text { Per } \\
\text { cent. }\end{array}$ & No. & $\begin{array}{l}\text { Per } \\
\text { cent. }\end{array}$ \\
\hline \multirow[t]{2}{*}{ Supplied } & $\begin{array}{l}\text { Anti-vermin } \\
\text { Compounds }\end{array}$ & 19 & $76 \cdot 0$ & 6 & $24 \cdot 0$ & 25 & 100 \\
\hline & Stain-removers & 66 & $53 \cdot 7$ & 57 & $46 \cdot 3$ & 123 & 100 \\
\hline \multirow{2}{*}{$\begin{array}{c}\text { Not } \\
\text { Supplied }\end{array}$} & $\begin{array}{c}\text { Furniture } \\
\text { Polishes }\end{array}$ & 66 & $51 \cdot 2$ & 63 & $48 \cdot 8$ & 129 & 100 \\
\hline & $\begin{array}{l}\text { Washing and } \\
\text { Washing-up } \\
\text { Materials }\end{array}$ & 24 & $13 \cdot 1$ & 159 & 86.9 & 183 & 100 \\
\hline
\end{tabular}


preparations-vermin destroyers-were found to be accessible in about one-quarter of the cases, an extremely high figure. The least poisonous preparations were stored accessibly in almost all families. The others were accessible in approximately half the families, whether they were marked with a warning or not.

It was found that twenty cases of poisoning had occurred among nineteen families of those studied. In spite of the recognition of the need for safety precautions which should follow with the occurrence of poisoning, fifteen of these families still stored their poisonous medicines and household chemicals in a very unsatisfactory way.

\section{Methods}

\section{Discussion}

As a contribution towards the study of the causes of accidental poisoning, an inventory was made of the medicines and household chemicals in use, the space available for storing such substances, and the use made of these storage spaces. The aim was to make objective observations, and to develop a method of investigation which could be repeated.

In attempting to make such assessments, considerable opposition might be expected on the part of the families interviewed, but this was not the case. Only two families refused to be interviewed. In the great majority the persons interviewed showed their cupboards and other storage spaces, often willingly, so that the information given could be checked. This success may be ascribed mainly to the good relations which already existed between the family and the interviewer, and the method used may be said to have yielded reliable information.

To assess the storage of poisons in individual homes uniformly and objectively it was necessary to construct special norms, which are discussed in more detail below.

The investigation covered families with children aged 1 to 2 years. The ability of the child to gain access to poisonous preparations naturally increases progressively during this second year of life. To judge exactly whether a preparation is accessible or not, the place of storage should be considered in relation to the development of the child. This should mean either that a graduated pattern must be set up with different demands of inaccessibility for different stages of development, which would involve a much too complicated system, or that every interviewer must himself make the assessment from case to case, which might result in varying bases of judgement.
Deliberately disregarding the great differences which may exist between the powers of children of the same age, it was decided to make the assessments according to what could be expected to be accessible to a 24-month-old child, and a simple and practical method was thus obtained. In a few families, however, the child was somewhat older than 24 months, and the norm used could be regarded as rather too lenient, while it was adequate or somewhat too strict in other families which included children little more than 12 months old. It would have been meaningless, however, to place the demands lower than the corresponding development level of 24 months, since in this case the preparations would have been accessible to many of the children. Indeed, it can be maintained that poisonous preparations should always be stored more safely than at the border of accessibility to a child of a certain age.

For other reasons also, the scheme of assessment must be regarded as rather rigid. A box of sleeping tablets left on a bedside table entails considerably more risk than one placed on the second shelf above the sink, which is still within the reach of a 2-yearold. Although there is a great difference in the degree of accessibility, it has not been possible, for practical reasons, to show the gradation of risks so revealed.

Thus the norms used are arbitrary from several aspects, but this systematization is unavoidable if the observations are to be objective and the investigation reproducible.

\section{Results}

The investigation showed first that the storage of medicines and household chemicals was very deficient in safety. Not more than 21 families (10.2 per cent.) stored these substances in an acceptable way, so that the great majority of the children of the town aged 1 to 2 years were exposed to the risk of poisoning.

The investigation showed that the equipment for storing poisons in the home was very unsatisfactory. Almost half of the modern homes lacked cleaning cupboards with locks. Even more obvious is the lack of cupboards with a lock under the sink, but in some homes attention had been paid to this question. For example, in three modern apartment blocks, practically all cupboards had been fitted with safety locks. A cupboard with a lock for medicines was found inside the cleaning cupboard in five households.

The investigation also showed that the existing safety arrangements were not used satisfactorily. Among the sixteen families with medicine cupboards there were six who did not use the cupboards for their 
poisonous medicines, and among the 71 families with cleaning cupboards provided with a lock there were 24 who did not use them for their household chemicals. Thus, strikingly enough, the homes with cleaning cupboards with locks had no better methods of storing household chemicals than those that lacked such cupboards.

Only in one home was the cleaning cupboard locked and the key removed-in other cases with "inaccessibility in the cleaning cupboard" the safe storage was due only to the fact that the chemicals were placed high up. Much more often the cleaning cupboard remained unlocked with the chemicals accessible on lower shelves; because of this an unlocked cleaning cupboard was a less satisfactory storage place than many other cupboards. The inadequate use of cleaning cupboards, perhaps because of their unpractical placing, and also the tendency in many homes to store household chemicals in several different places, contributed to the generally unsafe methods of storing household chemicals.

It is difficult to judge whether the propaganda has had any effect. In several families, however, the safety problem was a real one. Three of those in which no poisons were accessible ascribed this to a reaction following cases of poisoning. Eleven families had obtained medicine cupboards on their own initiative, and a few had themselves applied safety fittings to kitchen cupboards, etc., but not many safety locks and lids were found. But it is possible that increased propaganda has resulted first and foremost in better supervision of children. This factor, though important in the frequency of poisoning cases, lies outside the range of the present investigation. Good supervision should, however, not mean decreased necessity for safe storage of poisonous preparations.

It is evident from the investigation that medicines are generally stored more safely than household chemicals. Of the preparations with warning notices which were especially investigated, garden pest destroyers (chiefly nicotine preparations) were generally stored less accessibly than other poisonous compounds. This could be due partly to the clear "poison" notice and partly to the fact that the public has become conscious through propaganda that nicotine preparations are very dangerous.

The warning notices on most stain-removers did not, on the other hand, appear to lead to any safer storage of these substances compared with that of furniture polishes, which lack such notices. This possibly indicates that warning notices in themselves are of little significance compared with the general impression of danger achieved by the issue of information and newspaper accounts of accidents.

\section{Practical Consequences}

The unsatisfactory storage of medicines and household chemicals is associated with many obscure factors, and the reasons are often unclear. It is, however, evident that home equipment for storing poisons is unsatisfactory. That more has to be done to provide storage facilities in new homes was also suggested by McKendrick (1960) after his analysis of a series of poisoning cases. The fact that the existing space is often used ineffectively suggests that it is not adequately constructed and practically situated.

But equipment alone, however correct, is obviously not sufficient. Instruction on how and why locked cupboards should be used also seems to be necessary. Although medicine cupboards, safety stoppers, and safety locks are available in shops only a very few were found in the homes. Furthermore, warning notices on packages must be very clear, and preferably relevant to general experience and knowledge of the dangers to be of any use. Clearly, further information and propaganda are essential in the fight against the accidental poisoning of children.

\section{SUMMARY}

The aim of the present investigation was to conse struct an objective and replicable method of record-? ing poisoning risks to children in the home, and to apply this method practically, to assist in reducing the risk of accidental poisoning.

A 20 per cent. random selection in a town in middle Sweden of all families with children aged 1 to 2 years were visited at their homes, a total of 206 families. Inquiry was made about certain specified groups of poisonous medicines and household chemicals, and about the arrangements for storing poisons. The method of storage was assessed according to a schematic norm based on what could be considered inaccessible to a 24-month-old child.

The results showed that the storage of poisonous substances was very unsatisfactory. Suitable storage space for poisons was lacking, and where such space existed it was often inadequately used.

The issue of information and the use of propaganda must form an essential part of future work in the prevention of accidental poisoning in children.

With the method of investigation used it should be possible to carry out comparable estimations of the poisoning risks to children in the home at other periods and in other places. 


\section{REFERENCES}

Barr, M. (1958). Svenska Läk.-Tidn., 55, 3032.

Berfenstam, R. (1954). Socialmed. T., 31, 361. (1958). Med. Press, 239, 451.

, Ehrenpreis, T., Ekström, G., Garsten, P.. and Myrin, S.-O. (1957). Svenska Läk.-Tidn., 54, 1950. Christiansson, G. (1954). Ibid., 51, 2394. and Berfenstam, R. (1958). Ibid., 55, 3555.

Jacobziner, H. (1957). Postgrad. Med., 22, 283.

Karlsson, B. (1955). Nord. Med., 53, 894.
Koumans, A. J. R. (1960). Pediatrics, 25, 1067.

Lindquist, B. (1954). Svenska Läk.-Tidn., 51, 2080.

McIntire, M. S., and Simmons, D. (1960). "Home Visits by Public Health Nurses and Accidental Poisoning." Abstracts of papers presented at the second meeting of the American Association of Poison Control Centres, February, 1960, sid. 2.

McKendrick, T. (1960). Arch. Dis. Childh., 35, 127.

Myrin, S.-O., Berfenstam, R., and Karlsson, B. (1960). Svenska Läk.-Tidn., 57, 352. 